\title{
STRATEGI PROMOSI MELALUI MEDIA PERIKLANAN DESA WISATA KUBU GADANG KOTA PADANG PANJANG
}

\author{
Nindy Eka Putri ${ }^{1}$, Silfeni ${ }^{2}$, Feri Ferdian ${ }^{2}$ \\ Program Studi Manajemen Perhotelan \\ FPP Universitas Negeri Padang \\ Email: ekaputrinindy@gmail.com
}

\begin{abstract}
The purpose of this research is to analyze the promotion strategy through advertising media at Desa Wisata Kubu Gadang Kota Padang Panjang view from 3 indicator: print media, electronic media, outdoor media. The research is a descriptive qualitative with survey method. Determination of informant using purposive sampling and snowball sampling. The purposive sampling technique involving 2 informant from tourism govermant and 2 informant from desa wisata Kubu Gadang Kota Padang Panjang manager then snowball sampling technique involving 3 informant from desa wisata Kubu Gadang Kota Padang Panjang visitor. Technique of collecting data is done by interview, observation, and documentation. The results of this study indicate that: 1) the strength of promotion advertising are: news paper easy to get, the picture quality on brochure have a good and interesting, radio can be heard anywhere, television give information through sound and picture, desa wisata Kubu Gadang also have a website and a big billboard with a perfect lighting. 2) the weakness of promotion advertising are: there was no promotion through a brochure, there was no update on the Kubu Gadang's website, the billboard was vulnerable of damage. 3) the opportunities of promotion advertising are: there are many people who still interest to read the newspaper and brochure, there are many people who interest of internet using, many people can see the outdoor media as if billboard and baliho. 4) the threats of promotion advertising are: there are competitor through print media, television and outdoor media. The conclusion of The promotion strategy through advertising media at Desa Wisata Kubu Gadang Kota Padang Panjang is 1) making use of print media for promotion, 2) to increase the promotion thourgh radio, television and website/internet, 3) making advertising through outdoor media as if billboard and baliho.
\end{abstract}

Keyword: Promotion Strategy, Advertising Media, Desa Wisata.

\section{PENDAHULUAN}

Saat ini pariwisata telah menjadi kebutuhan bagi masyarakat di berbagai lapisan bukan hanya untuk kalangan tertentu saja, sehingga dalam penanganannya harus dilakukan dengan serius dan melibatkan pihak-pihak yang terkait. Dalam hal ini industri pariwisata berlomba-lomba menciptakan produk pariwisata yang lebih bervariasi menyangkut pelestarian dari objek itu sendiri sesuai dengan tujuan 
pembangunan pariwisata yaitu untuk mengenalkan keindahan alam, budaya dan adat istiadat yang beraneka ragam. Salah satu cara yang dapat digunakan dalam memasarkan atau menjual sebuah produk pariwisata ke konsumen ialah melalui promosi. Salah satu yang mempengaruhi promosi yaitu media periklanan.

Menurut Suryadi (2013:8),
"Promosi ialah kegiatan untuk
mengkomunikasikan,
pengetahuan dan meri
konsumen tentang suatu produk agar mengakui kehebatan produk tersebut, membeli dan memakai produk tersebut, juga mengikat pikiran dan perasannya dalam suatu wujud loyalitas suatu produk". Periklanan dipandang sebagai salah satu media promosi yang paling efektif dalam mengkomunikasikan barang dan jasa. Menurut Achroni (2015:109), "Periklanan adalah bentuk promosi nonpersonal atas barang dan jasa dengan menggunakan media tertentu, yang ditujukan untuk mendorong pembelian". Periklanan sangat berpengaruh terhadap promosi wisata, karena dengan adanya periklanan suatu wisata dapat dikenal dan dikunjungi oleh para wisatawan lokal maupun mancanegara.

Sumatera Barat merupakan salah satu Provinsi di Indonesia yang memilki banyak potensi wisata yang indah dan beragam yang dikelilingi oleh pantai dan pegunungan yang memiliki keaslian pedesaan baik dari kehidupan sosial ekonomi, sosial budaya, adat istiadat. Desa wisata Kubu Gadang terletak di
Jalan Haji Miskin, Kelurahan Ekor Lubuk Kecamatan Padang Panjang Timur Kota Padang Panjang. Desa Kubu Gadang sangat menjunjung adat istiadat minangkabau yang memiliki berbagai kuliner dan budaya dengan nuansa adat Minangkabau asli dari kota Padang Panjang Sumatera Barat.

Adapun paket kuliner yang tersedia yaitu makan bajamba dan makan baradaik, atraksi budaya seperti kegiatan masyarakat contohnya baronde. Atraksi kesenian berupa Silek lanyah yang menjadi andalan desa wisata Kubu Gadang, Desa Kubu Gadang juga memiliki kegiatan wisata pendidikan yang dikembangkan kepada paket wisata yang disebut dengan $e d u$ turism dan melestarikan sebuah permainan tradisional yaitu pacu upiah.

Desa wisata Kubu Gadang juga menyediakan penginapan/homestay serta fasilitas penunjang lainnya seperti gedung pertemuan, sarana kesehatan, gazebo/pondokan untuk acara pertemuan. Berdasarkan dari hasil pra penelitian pada tanggal 15 April 2017 dengan 10 orang pengunjung yang berkunjung ditemui beberapa masalah. Sebanyak $70 \%$ wisatawan menyataka belum ada penyebaran brosur desa wisata Kubu Gadang sehingga belum mengena pada sasaran yang membuat banyak yang tidak mengetahui adanya Desa Wisata Kubu Gadang. Permasalahan selanjutnya 50\% wisatawan menyatakan tidak adanya kalender event pariwisata untuk desa wisata Kubu Gadang, 40\% wisatawan menyatakan belum adanya iklan desa 
wisata Kubu Gadang di media elektronik seperti radio padahal radio dapat menjangkau secara luas. Permasalahan lainnya $60 \%$ wisatawan menyatakan banyak pengguna internet saat ini tidak mengetahui adanya desa wisata atau web desa wisata Kubu Gadang disebabkan karena kurang maksimalnya periklanan melalui media internet/web, permasalahan berikutnya $50 \%$ wisatawan menyatakan tidak ditemuinya iklan melalui media outdoor seperti tidak terdapat bahilo ataupun billboard di tempat-tempat yang di anggap strategis untuk mempublikasikan atau mempromosikan di sepanjang jalan yang manarik wisatawan untuk berkunjung.

Urgensi penelitian ini bagi Dinas Pariwisata Kota Padang Panjang dan pengelola desa wisata Kubu Gadang untuk lebih meningkatkan promosi desa wisata Kubu Gadang agar dapat menambah jumlah kunjungan wisatawan, dan menambah pendapatan masyarakat serta meningkatkan kesejahteraan masyarakat disekitar desa wisata.

\section{METODE PENELITIAN}

Jenis penelitian ini adalah penelitian deskriptif dengan data kualitatif dengan menggunakan metode survey. Teknik pengumpulan data dilakukan dengan menggunakan metode wawancara, observasi dan dokumentasi. Dalam penelitian ini untuk menentukan informan menggunakan teknik purposive sampling dan snowball sampling. Teknik purposive sampling dengan melibatkan informan dua orang dinas pariwisata dan dua orang pengelola desa wisata Kubu Gadang serta teknik snowball sampling yaitu tiga orang pengunjung desa wisata Kubu Gadang. Jenis data dalam penelitian ini adalah data primer dan data sekunder. Data primer berkaitan dengan strategi promosi melalui media periklanan desa wisata Kubu Gadang dimana pengambilan data dilakukan secara langsung oleh peneliti terhadap sasaran. Data Sekunder adalah data yang diperoleh secara tidak langsung yaitu melalui dokumen atau melalui perantara, data sekunder tersebut mengenai gambaran umum tentang desa wisata Kubu Gadang. Teknis analisis data yang digunakan dalam penelitian ini adalah reduksi data, penyajian data, dan penarikan kesimpulan.

\section{HASIL PENELITIAN DAN PEMBAHASAN}

\section{Hasil Penelitian}

Temuan dalam penelitian dapat dibagi dua jenis: 1) Temuan umum bersifat menyeluruh, 2) temuan yang bersifat khusus tentang strategi promosi melalui media periklanan desa wisata Kubu Gadang Kota Padang Panjang yang terdiri atas media cetak, media elektronik dan media outdoor yang dilihat melalui analisis SWOT yang berupa kekuatan, kelemahan, peluang dan ancaman.

\section{a. Media cetak}

1) Koran

Kekuatan dari media cetak koran ialah 
harga media cetak koran mudah terjangkau, koran mudah di dapat serta jangkauan koran lebih luas. Kelemahan dari media cetak koran ialah media cetak koran kurang menarik, kualitas cetakan gambar pada koran kurang bagus. Peluang dari koran ialah masih banyaknya peminat yang membaca media cetak koran umumnya pada kalangan dewasa dan ancaman kurangnya minat baca koran pada kalangan remaja

\section{2) Brosur}

Kekuatan dari media brosur ialah brosur memiliki kualitas cetakan gambar yang menarik dan harga dalam pembuatan brosur relatif murah, kelemahan promosi melalui brosur ialah belum ada promosi desa wisata Kubu Gadang melalui media brosur dan brosur cederung diabaikan jika isinya kurang menarik. Peluang dari media brosur ialah masih banyak peminat untuk membaca brosur dan ancamannya brosur yang dibuat dari pihak lain lebih bagus dan menarik.

\section{b. Media elektronik}

\section{1) Radio}

melalui radio ialah biaya melakukan promosi melalui radio relatif rendah dan radio dapat didengar dimana saja dan kapan saja. Kelemahan promosi melalui radio ialah iklan melalui radio tidak mengemukakan gambar dan belum ada promosi melalui radio yang khusus untuk desa wisata Kubu Gadang. Peluang dari radio ialah masih banyak peminat yang pendengar radio dan ancamannya banyak alternatif pendengar dalam pemilihan stasiun radio.

\section{2) Televisi}

Kekuatan promosi melalui media televisi ialah televisi dapat menyampaikan pesan melalui suara dan gambar serta iklan melalui media televisi dapat menjangkau banyak orang pada tingkat nasional. Kelemahan promosi melalui televisi ialah biaya yang relatif tinggi dalam melakukan promosi dan iklan melalui televisi hanya dapat dinikmati sebentar. Peluang promosi melalui televisi ialah televisi memiliki jangkauan yang luas sehingga perhatian audiens terhadap media televisi tinggi dan ancamannya iklan melalui media televisi dari pihak lain lebih menarik. 


\section{3) Web/intenet}

Kekuatan promosi melalui web/internet ialah biaya untuk melakukan promosi melalui web/internet relatif murah dan mudah untuk diakses, kelemahan promosi melalui web/internet ialah jaringan pada internet terbatas serta belum adanya pembaharuan website desa wisata Kubu Gadang. Peluang promosi melalui web/internet ialah tingginya minat pengguna internet baik masyarakat lokal maupun mancanegara dan ancaman yang tidak menguntungkan melakukan promosi melalui web/internet ialah adanya persaingan dari pihak lainnya dalam melakukan promosi melalui web/internet.

\section{c. Media Outdoor}

Kekuatan promosi melalui media outdoor seperti billboard dan baliho ialah ukuran yang besar dan pencahayaan yang sempurna, ditempatkan dilokasi yang dianggap strategis yang banyak dilalui khalayak ramai serta pesan yang disampaikan jelas. Kelemahan promosi melalui media billboard dan baliho seperti pesan yang disampaikan terbatas dan rentan terhadap perusakan serta iklan melalui baliho sifatnya sementara. Peluang promosi melalui media outdoor ialah banyak orang dengan mudah melihat iklan melalui billboard dan baliho dan acamannya terdapat persaingan promosi melalui billboard baik dari sesama daerah Padang Panjang maupun dari pihak luar.

\section{Pembahasan}

a. Koran/surat kabar

Berdasarkan hasil wawancara dari penelitian, iklan desa wisata Kubu Gadang belum dimuat di media cetak koran tetapi hanya ada ketika event-event tertentu saja. Menurut hasil wawancara keunggulan dari media cetak koran ialah harga media cetak koran mudah terjangkau dan mudah di dapat serta masih banyaknya peminat yang membaca media cetak koran. Kekurangan dari media cetak koran ialah media cetak koran kurang menarik dan mudah diabaikan apalagi pada kalangan remaja. Maka strategi promosi melalui media cetak koran yang dapat dilakukan ialah memanfaatkan media cetak koran sebagai media promosi untuk desa wisata Kubung Gadang karena masih banyak peminat yang membaca koran pada kalangan dewasa dan lanjut usia serta harga media cetak koran mudah terjangkau. Hal ini sesuai dengan teori yang dikemukan oleh Shimp (2003:15) "Koran/surat kabar bersifat fleksibel dan tepat waktu, ukuran dapat bervariasi, biaya perorang yang terjangkau dan relatif murah". 


\section{b. Brosur}

Berdasarkan

hasil

wawancara dari penelitian, promosi melalui media brosur untuk desa wisata Kubu Gadang belum ada. Menurut hasil wawancara keunggulan dari media brosur ialah brosur memiliki kualitas cetakan gambar yang menarik dan harga dalam pembuatan brosur relatif murah serta masih banyak peminat untuk membaca brosur. Kelemahan dan ancaman yang tidak menguntungkan promosi melalui brosur ialah belum ada promosi desa wisata Kubu Gadang melalui media brosur dan terdapat persaingan dari pihak lain dengan brosur yang lebih menarik. Maka strategi promosi melalui media brosur yang dapat dilakukan ialah dengan membuat brosur desa wisata Kubu Gadang yang memiliki kualitas cetakan gambar yang bagus dan menarik sehingga wisatawan tertarik untuk membaca dan dapat mengetahui apa saja atraksi seni dan budaya yang ditawarkan desa wisata Kubu Gadang Kota Padang Panjang. Hal ini sesuai dengan teori yang dikemukakan oleh Yoety (1996: 192), "Brosur merupakan selebaran dengan menggunakan kertas yang relative baik, lay out yang disusun menarik, dengan segala potensi yang hendak di promosikan".

\section{c. Radio}

Berdasarkan hasil wawancara dari penelitian, iklan desa wisata Kubu Gadang belum ada di media elektronik seperti radio tetapi hanya ada ketika event-event tertentu saja. Menurut hasil wawancara kekuatan promosi melalui radio ialah biaya melakukan promosi melalui radio relatif rendah dan radio dapat didengar dimana saja dan kapan saja. Kelemahan dan ancaman yang tidak menguntung melakukan promosi melalui radio ialah iklan melalui radio tidak mengemukakan gambar dan banyak alternatif pendengar dalam pemilihan stasiun radio. Maka strategi promosi melalui media radio yang dapat dilakukan ialah memuat iklan desa wisata Kubu Gadang di media radio dengan kreatifitas dan inovatif agar audiens tertarik mendengarkan iklan di radio yang bisa didengar dimana saja dan kapan saja. Hal ini sesuai dengan teori yang dikemukakan Shimp (2003:16), "Radio dapat di dengar dimanapun, biaya produksi iklan radio sangat murah dan sangat fleksibel sehingga dapat di manfaatkan untuk memenuhi kebutuhan konsumen, efektif untuk menjangkau pasar sasaran tertentu".

\section{d. Televisi}

Berdasarkan hasil wawancara dari penelitian, iklan desa wisata Kubu Gadang melalui media televisi nasional dan daerah sudah ada. Menurut hasil wawancara kekuatan promosi melalui media televisi ialah televisi dapat menyampaikan pesan melalui suara dan gambar serta televisi 
memiliki jangkauan yang luas sehingga perhatian audiens terhadap media televisi tinggi. Kelemahan dan ancaman tidak menguntungkan melakukan promosi melalui televisi ialah biaya yang relatif tinggi dalam melakukan promosi dan iklan melalui media televisi dari pihak lain lebih menarik. Maka strategi promosi yang dapat dilakukan melalui televisi ialah memanfaatkan televisi sebagai media promosi yang menyampaikan pesan melalui suara dan gambar yang dapat menarik audiens untuk melihat dan membaca iklan melalui televisi. Hal ini sesuai dengan teori yang dikemukan oleh Kotler \& Keller (2012:479), "Televisi merupakan salah satu media yang termasuk dalam kategori above the line, iklan televisi memiliki keunggulan menggabungkan gambar suara gerakan yang merangsang indra dan memliki jangkauan yang luas".

\section{e. Web/internet}

Berdasarkan

hasil wawancara dari penelitian, web/internet sudah ada tetapi belum ada pembaharuan website desa wisata Kubu Gadang. Menurut hasil wawancara kekuatan promosi melalui web/internet ialah biaya untuk melakukan promosi melalui web/internet relatif murah dan mudah terjangkau serta tingginya minat pengguna internet baik masyarakat lokal maupun mancanegara. Kelemahan dan ancaman yang tidak menguntungkan melakukan promosi melalui web/internet ialah jaringan pada internet terbatas dan adanya persaingan dari pihak lainnya dalam melakukan promosi melalui web/internet. Maka strategi promosi melalui web/internet yang dapat dilakukan ialah meningkatkan promosi desa wisata Kubu Gadang di media web/internet dengan melakukan pembaharuan website desa wisata Kubu Gadang yang memuat informasi dan dokumentasi terbaru seputar desa wisata Kubu Gadang yang dapat dilihat oleh masyarakat lokal maupun mancanegara. Hal ini sesuai dengan teori yang dikemukan oleh Suryadi (2013:115), "Perkembangan teknologi informasi khususnya internet mengalami pertumbuhan semakin hari semakin pesat, dari sisi teknologi akses internet bisa dilakukan selama 24 jam setiap hari, karena itu internet semakin di gemari para pemasar untuk mempromosikan produknya".

\section{f. Media Outdoor}

Berdasarkan hasil wawancara dari penelitian, promosi melalui media outdoor seperti billboard dan baliho belum ada tetapi hanya ada ketika event - event tertentu saja. Menurut hasil wawancara kekuatan dan peluang promosi melalui media outdoor seperti billboard dan baliho ialah ukuran yang besar dan pencahayaan yang sempurna, di tempatkan dilokasi yang dianggap strategis 
yang banyak dilalui khalayak ramai. Kelemahan dan ancaman yang tidak menguntung melakukan promosi melalui media billboard seperti pesan yang disampaikan terbatas dan rentan terhadap kerusakan serta terdapat persaingan promosi melalui billboard baik dari sesama daerah Padang Panjang maupun dari pihak luar. Maka strategi promosi melalui media outdoor yang dapat dilakukan ialah dengan membuat promosi desa wisata Kubu Gadang melalui billboard dan baliho dengan ukuran yang besar serta pencahayaan yang sempurna dan memanfaatkan lokasi yang dianggap strategis yang banyak dilalui khalayak ramai agar dapat melihat dan membaca iklan desa wisata Kubu Gadang melalui media outdoor. Hal ini sesuai dengan teori yang dikemukakan oleh Shimp (2003:16), "Media outdoor merupakan iklan yang dibuat ataupun yang dilakukan diluar ruangan untuk mempublikasikan atau mempromosikan bisnis, produk, atau jasa yang berupa billboard, baliho dan spanduk".

\section{KESIMPULAN DAN SARAN}

\section{Kesimpulan}

Secara keseluruhan dapat diambil kesimpulan mengenai strategi promosi melalui media periklanan desa wisata Kubu Gadang Kota Padang Panjang dengan menentukan faktor internal periklanan yang meliputi kekuatan dan kelemahan, serta faktor eksternal periklanan yang meliputi peluang dan ancaman. Kemudian merumuskan strategi promosi melalui media periklanan desa wisata Kubu Gadang Kota Padang Panjang

\section{Saran}

Bagi Dinas Pariwisata Kota Padang Panjang agar dapat bekerja sama dengan pengelola desa wisata Kubu Gadang dalam hal promosi desa wisata Kubu Gadang seperti: memanfaatkan media cetak untuk melakukan promosi, memuat iklan desa wisata Kubu Gadang melalui radio dan televisi, meningkatkan promosi melalui media web/internet, membuat iklan desa wisata Kubu Gadang melalui media billboard dan baliho.

Bagi jurusan pariwisata hasil penelitian ini diharapkan untuk dapat menjadi bahan untuk menambah wawasan dan ilmu pengetahuan. Serta menjadi informasi yang memadai khusunya bagi pihak terkait dan menjadi bahan pembelajaran. Dilihat dari besarnya peluang kerja dibidang pariwisata, diharapkan jurusan pariwisata dapat menfokuskan mahasiswa dalam perkuliahan tentang kepariwisataan agara dapat menciptakan sumber daya manusia yang professional.

Bagi peneliti berikutnya diharapkan dapat melanjutkan penelitian mengenai strategi promosi melalui media periklanan dan dapat menjadi dasar peneliti 
lanjutan seperti strategi

pengembangan promosi desa wisata Kubu Gadang Kota Padang Panjang dan aktifitas bauran promosi di desa wisata Kubu Gadang)

\section{DAFTAR PUSTAKA}

Achroni, Keen. 2015. Tips Cerdik Menggetjot Penjualan dan Omzet. Yogyakarta: Literindo.

Kotler, Philip and Keller. 2012. Marketing Management. Edisi 14 Global. New Jersey. Pearson Prentice Hall

Shimp, Terence A. 2003. Periklanan dan Promosi. Jakarta: Erlangga.

Suryadi, Didih. 2013. Promosi Efektif Menggugah Minat \& Loyalitas Pelanggan. Platinum.

Yoeti, Oka A. 1996. Pemasaran Pariwisata. Bandung: Angkasa. 